\title{
Atypical presentation of Pneumocystis jirovecii pneumonia in a patient with rheumatoid arthritis treated with tofacitinib: a case presentation
}

\author{
lan F. J. Pirker ${ }^{1^{*}}$ D, Jacqueline Krane-Nuber ${ }^{1}$, Werner C. Albrich², Rüdiger Müller ${ }^{3}$ and Thomas Neumann ${ }^{3}$
}

\begin{abstract}
Background: We report the case of a patient with rheumatoid arthritis (RA) treated with tofacitinib who developed severe Pneumocystis jirovecii pneumonia (PJP) with an atypical clinical presentation.

Case presentation: A 78-year old male patient with RA treated with tofacitinib, methotrexate (MTX) and low dose corticosteroids was admitted to the hospital with arthralgia and nausea. Laboratory findings revealed hypercalcemia with normal levels of parathyroid hormone $(\mathrm{PTH})$ and elevated 1,25-(OH) 2 vitamin D levels. A lung CT scan showed bilateral interstitial pneumonic infiltrates. PCR from bronchoalveloar lavage was positive for Pneumocystis jirovecii. Hypercalcemia resolved under PJP treatment and was - after exclusion of other possible causes - probably fungal associated.
\end{abstract}

Conclusion: Due to the increased risk of opportunistic infections in immunocompromised patients, the finding of hypercalcemia in conjunction with a pulmonary infection should raise high clinical suspicion of PJP.

Keywords: Pneumocystis jirovecii pneumonia, Rheumatoid arthritis, Tofacitinib, Hypercalcemia

\section{Background}

Pneumocystis jirovecii pneumonia (PJP) is a potentially life-threatening opportunistic fungal infection in immunocompromised patients. While it was an important opportunistic infection in the early HIV era prior to effective antiretroviral therapy, it is increasingly seen now in patients not infected with HIV with relevant morbidity and mortality [1]. However, non-HIV infected patients with PJP tend to have more acute presentations than HIV-infected patients [1].

Hypercalcemia can develop under several conditions, including hyperparathyroidism, osteolytic bone lesions or granulomatous diseases, but has also been described with infections, especially with PJP in patients with renal transplants [1].

\footnotetext{
* Correspondence: ian.pirker@kssg.ch

${ }^{1}$ Department of Internal Medicine, Cantonal Hospital St. Gallen, St. Gallen, Switzerland

Full list of author information is available at the end of the article
}

We searched PubMed using following terms: Pneumocystis jirovecii AND hypercalcemia. Two case reports were listed. No literature on "hypercalc" AND rheumatoid arthritis AND Pneumocystis (jirovecii OR carinii) AND tofacitinib" or on "hypercalc* AND Pneumocystis (jirovecii OR carinii) AND tofacitinib" were identified.

Here we report the first case to our knowledge of a patient with RA treated with tofacitinib who presented with hypercalcemia as a leading symptom of PJP.

\section{Case presentation}

A 78-year old male patient with RA treated with tofacitinib (10 mg p.o. daily), methotrexate (20 mg p.o. weekly) and low dose corticosteroids (prednisolone $5 \mathrm{mg}$ p.o. daily), was admitted to hospital with a 2-week history of arthralgia, nausea and confusion (Additional file 1). RA was diagnosed 6 months ago, as the patient fulfilled the 2010 ACR/EULAR classification criteria with bilateral symmetric swollen and tender joints (wrists, hands and feet; over 10 affected joints in total) and arthralgia for 
3 years (negative anti-CCP antibody and negative rheumatoid factor IgM). No signs of erosions were found on X-ray (hands and feet). Therapy was initiated with prednisone $(20 \mathrm{mg} /$ day) and MTX $15 \mathrm{mg} /$ week s.c. with increasing doses over time. Tofacitinib was initiated 2 months prior hospital admission due to lack of efficacy of MTX monotherapy (MTX was switched to p.o. at that time, as the patient disliked injections).

At time of admission the patient reported shortness of breath on exertion but not at rest.

Physical examination showed following vital signs: temperature (auricular): $36.5{ }^{\circ} \mathrm{C}$ blood pressure: $178 /$ $95 \mathrm{mmHg}$, heart rate: $75 \mathrm{bpm}$, oxygen saturation: $88-$ $90 \%$ at rest and on exercise $80 \%$ on room air. Wrists and ankles were swollen and tender bilaterally symmetric. There were normal findings on auscultation of heart and lungs without any other signs of venous congestion.

Laboratory findings on admission revealed hypercalcemia (albumin-corrected $3.12 \mathrm{mmol} / \mathrm{l}$ (normal range 2.0 $2.6 \mathrm{mmol} / \mathrm{l}$ ) and elevated 1,25- dihydroxyvitamin D levels (162 ng/l, normal range 22-111 ng/l). PTH was appropriately low at $<0.5 \mathrm{pmol} / \mathrm{l}$ (normal range $<1.3 \mathrm{pmol} / \mathrm{l}$ ). Further laboratory findings are described in Table 1.

Further investigation of hypercalcemia included a whole body CT scan, which showed bilateral interstitial pneumonic infiltrates without pleural effusions (Fig. 1). The patient was referred from normal ward care to the ICU due to acute respiratory failure requiring non-invasive ventilation/ high-flow oxygen therapy. PCR from bronchoalveloar lavage (BAL) was positive for $P$. jirovecii and Rhinovirus $\mathrm{A} / \mathrm{B} / \mathrm{C}$ and a diagnosis of PJP was made with colonization of Rhinovirus. Adequate therapy with TMP/SMX i.v. (15 mg/kg/d) and prednisolone p.o. $(1 \mathrm{mg} / \mathrm{kg} / \mathrm{d})$ was initiated. Treatment with TMP/SMX was stopped after 10 days because of severe hyponatremia (drop from $136 \mathrm{mmol} / \mathrm{l}$ to $119 \mathrm{mmol} / \mathrm{l}$; normal range 136-144 mmol/l) and acutely worsening confusion, which was attributed most likely to acute hyponatremia or as a direct adverse drug reaction to TMP/SMX. As second line therapy we initiated clindamycin and primaquine. Confusion

Table 1 parathyroid hormone, CRP: C-reactive protein

\begin{tabular}{lll}
\hline $\begin{array}{l}\text { Laboratory parameter } \\
\text { (units) }\end{array}$ & $\begin{array}{l}\text { findings at } \\
\text { admission }\end{array}$ & $\begin{array}{l}\text { normal } \\
\text { range }\end{array}$ \\
\hline Calcium (mmol/L) & 2.8 & $2.0-2.6$ \\
Albumine $(\mathrm{g} / \mathrm{l})$ & 27.1 & $34-48$ \\
Intact PTH $(\mathrm{ng} / \mathrm{l})$ & 15.3 & $15-65$ \\
PTH related peptide $(\mathrm{pmol} / \mathrm{l})$ & $<0.5$ & $<1.3$ \\
1,25-dihyroxyvitamin D (ng/l) & 162 & $22-111$ \\
25-OH vitamin D total $(\mathrm{mmol} / \mathrm{l})$ & 100 & $75-250$ \\
CRP $(\mathrm{mg} / \mathrm{l})$ & 148 & $<5$ \\
Procalcitonin quantitative $(\mathrm{microg} / \mathrm{l})$ & 0.29 & $<0.5$ \\
\hline
\end{tabular}

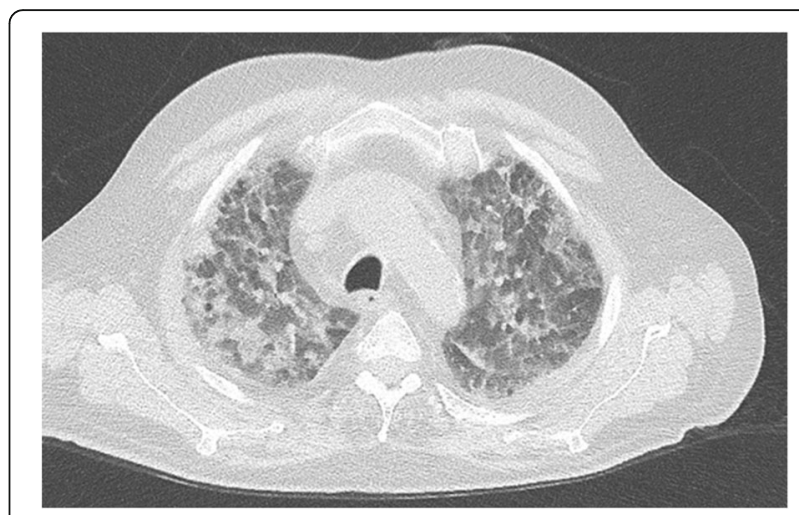

Fig. 1 CT scan with bilateral pneumonic infiltrates

improved but thrombocytopenia developed (drop from $441 \mathrm{G} / \mathrm{l}$ to $83 \mathrm{G} / \mathrm{l}) 4$ days later, which was felt to be due to primaquine and led to the discontinuation of clindamycin and primaquine.

Both the patient's clinical condition and hypercalcemia were improved after 17 days of antibiotic therapy. PJPprophylaxis with monthly inhaled pentamidin $(300 \mathrm{mg})$ was initiated.

\section{Discussion and conclusion}

We report for the first time a case of PJP in a tofacitinib treated RA patient that led to hypercalcemia. Physiologically, 1- alpha hydroxylation of $25-\mathrm{OH}$ vitamin $\mathrm{D}$ occurs primarily in the proximal renal tubule in response to PTH [2]. This step should have been inhibited fully in our patient by the low serum PTH value and the high serum calcium and normal phosphate. Extrarenal 1-alpha hydroxylation of $25-\mathrm{OH}$ vitamin D occurs in macrophages driven by interferon-gamma (IFN- $\gamma$ ) in neoplastic, granulomatous and infectious diseases [3]. This latter mechanism most likely explains the hypercalcemia associated with high 1,25-dihydroxyvitamin D levels.

It is postulated that in infectious diseases granulomaforming activated macrophages can increase the conversion of $25-\mathrm{OH}$ vitamin $\mathrm{D}$ to 1,25 - dihydroxyvitamin D [3]. Normal macrophages do not produce 1,25-dihydroxyvitamin $\mathrm{D}$, but 1-alpha hydroxylation of $25-\mathrm{OH}$ vitamin $\mathrm{D}$ can be induced in macrophages exposed to IFN- $\gamma$, which is elevated in patients with PJP as shown in a study with pediatric patients [4].

In general, patients with RA are at increased risk to acquire infection in comparison to non RA study subjects due to the use of immunosuppressive therapy and/ or the immunomodulatory effects of RA itself [5]. Long term safety reports regarding opportunistic infections (including PJP) among patients with RA using tofacitinib revealed a risk of infection, although the incidence rate is low and it is uncertain if this risk differs from that observed with bDMARDs $[6,7]$. 
Recommendations on PJP prophylaxis in HIV negative patients with rheumatoid arthritis vary by author and region. A review by Wolfe et al. did not recommend PJP prophylaxis in patients with RA considering the low incidence of PJP in European and American patients [8].

In contrast, Mori et al. recommended short-term prophylaxis with TMP/SMX for patients with RA and newly treated with a biological and/or non-biological therapy [9].

A commonly encountered criterion to indicate PJP prophylaxis in non-HIV infected patients is receipt of prednisone $\geq 20 \mathrm{mg} / \mathrm{kg} / \mathrm{d}$ for $\geq 1$ month in addition to a second immunosuppressive or cytotoxic medication or a T-cell defect [10].

A recent study by Yukawa et al. proposes a scoring system based on usage of MTX, old age, number of immunosuppressive drugs, and dosage of prednisone, as these parameters were identified as risk factors of PJP in patients with rheumatoid arthritis [11]. A retrospective study showed that TMP/SMX prophylaxis significantly reduced PJP incidence in patients with rheumatic diseases (especially in patients receiving high dose steroids (over $60 \mathrm{mg} /$ day) [12]. Based on this study Winthrop et al. identified following risk factors for PJP in patients treated with glucocorticoids: lymphopenia, initial glucocorticoid dose $>60 \mathrm{mg} /$ day, current use of cyclophosphamide, anti TNF or rituximab use and presence of dermatomyositis, granulomatosis with polyangiitis and microscopic polyangiitis, while considering PJP prophylaxis at lower glucocorticoid doses $(15 \mathrm{mg})$ when risk factor are present [13].

However, an international survey revealed that in 2010 of 3150 consecutive members of the American College of Rheumatology (ACR), 30\% of surveyed rheumatologist reported that they never prescribed prophylaxis [14].

Hypercalcemia in patients with RA treated with immunosuppressive drugs in accordance with a pulmonary infection should raise high suspicion of PJP. Considering the potentially fatal courses of PJP, empirical treatment with TMP/SMX should be started in patients with sufficient clinical suspicion and should not be delayed until diagnostic procedures are performed or test results return. Evidence-based guidelines for PJP prophylaxis for the patients with autoimmune or connective tissue disease are urgently needed.

\section{Additional file}

Additional file 1: Timetable of patient care. (DOCX $94 \mathrm{~kb}$ )

\section{Abbreviations}

ACR: American College of Rheumatology; BAL: Bronchoalveloar lavage; CRP: C-reactive protein; HIV: Human immunodeficiency virus;

MTX: Methotrexate; PCP: Pneumocystis jirovecii pneumonia; PCR: Polymerase chain reaction; PTH: Parathyroid hormone; RA: Rheumatoid arthritis; TMP/

SMX: Trimethoprim/sulfamethoxazole

\section{Acknowledgements}

We gratefully acknowledge A. Thieme A. M.D. and El Baz Y. M.D., Department of Radiology, Cantonal Hospital St. Gallen, Switzerland for providing the CT image for this article.

\section{Funding}

This research received no specific grant from any funding agency in the public, commercial, or not-for-profit sectors.

Availability of data and materials

All data generated or analysed during this case report are included in this published article.

\section{Authors' contributions}

IP was involved in treating the patient, in drafting and writing the manuscript and made substantial contributions to conception and design. JK, WA and RM were involved in treating the patient (interdisciplinary) and were major contributors in writing the manuscript and critically revising the manuscript for important intellectual content. TN was involved in treating the patient, critical revising for important intellectual content and has given final approval of the manuscript. All authors read and approved the final manuscript.

Ethics approval and consent to participate

Not applicable.

\section{Consent for publication}

A signed patient consent form was obtained from the patient prior to submission of this case presentation.

\section{Competing interests}

The authors declare that they have no competing interests.

\section{Publisher's Note}

Springer Nature remains neutral with regard to jurisdictional claims in published maps and institutional affiliations.

\section{Author details}

${ }^{1}$ Department of Internal Medicine, Cantonal Hospital St. Gallen, St. Gallen, Switzerland. ${ }^{2}$ Division of Infectious Diseases \& Hospital Epidemiology, Cantonal Hospital St. Gallen, St. Gallen, Switzerland. ${ }^{3}$ Department of Rheumatology, Immunology and Rehabilitation, Cantonal Hospital St. Gallen, St. Gallen, Switzerland.

Received: 1 December 2017 Accepted: 23 October 2018

Published online: 03 November 2018

\section{References}

1. Roux A, Canet E, Valade S, Gangneux-Robert F, Hamane S, Lafabrie A, Maubon D, Debourgogne A, Le Gal S, Dalle F, et al. Pneumocystis jirovecii pneumonia in patients with or without AIDS, France. Emerg Infect Dis. 2014:20(9):1490-7.

2. Anderson PH, May BK, Morris HA. Vitamin D metabolism: new concepts and clinical implications. Clin Biochem Rev. 2003;24(1):13-26.

3. Adams JS, Rafison B, Witzel S, Reyes RE, Shieh A, Chun R, Zavala K, Hewison M, Liu PT. Regulation of the extrarenal CYP27B1-hydroxylase. J Steroid Biochem Mol Biol. 2014;144:22-7.

4. Shen HP, Tang YM, Song H, Xu WQ, Yang SL, Xu XJ. Efficiency of interleukin 6 and interferon gamma in the differentiation of invasive pulmonary aspergillosis and pneumocystis pneumonia in pediatric oncology patients. Int J Infect Dis. 2016;48:73-7.

5. Doran MF, Crowson CS, Pond GR, O'Fallon WM, Gabriel SE. Frequency of infection in patients with rheumatoid arthritis compared with controls: a population-based study. Arthritis Rheum. 2002;46(9):2287-93.

6. Winthrop KL, Park SH, Gul A, Cardiel MH, Gomez-Reino JJ, Tanaka Y, Kwok K, Lukic T, Mortensen E, Ponce de Leon D, et al. Tuberculosis and other opportunistic infections in tofacitinib-treated patients with rheumatoid arthritis. Ann Rheum Dis. 2016;75(6):1133-8.

7. Cohen SB, Tanaka Y, Mariette X, Curtis JR, Lee EB, Nash P, Winthrop KL, Charles-Schoeman C, Thirunavukkarasu K, DeMasi R, et al. Long-term safety of tofacitinib for the treatment of rheumatoid arthritis up to 8.5 years: 
integrated analysis of data from the global clinical trials. Ann Rheum Dis. 2017:76(7):1253-62.

8. Wolfe RM, Peacock JE Jr. Pneumocystis pneumonia and the rheumatologist: which patients are at risk and how can PCP be prevented? Curr Rheumatol Rep. 2017;19(6):35

9. Mori S, Sugimoto M. Pneumocystis jirovecii pneumonia in rheumatoid arthritis patients: risks and prophylaxis recommendations. Clin Med Insights Circ Respir Pulm Med. 2015;9(Suppl 1):29-40.

10. Limper AH, Knox KS, Sarosi GA, Ampel NM, Bennett JE, Catanzaro A, Davies SF, Dismukes WE, Hage CA, Marr KA, et al. An official American Thoracic Society statement: treatment of fungal infections in adult pulmonary and critical care patients. Am J Respir Crit Care Med. 2011;183(1):96-128.

11. Yukawa K, Nagamoto Y, Watanabe H, Funaki M, Iwahashi M, Yamana Sasaki R, Yamana S. Risk factors for pneumocystis jirovecii pneumonia in patients with rheumatoid arthritis and a prophylactic indication of trimethoprim/sulfamethoxazole. J Clin Rheumatol. 2018;24(7):355-60.

12. Park JW, Curtis JR, Moon J, Song YW, Kim S, Lee EB. Prophylactic effect of trimethoprim-sulfamethoxazole for pneumocystis pneumonia in patients with rheumatic diseases exposed to prolonged high-dose glucocorticoids. Ann Rheum Dis. 2018;77(5):644-9.

13. Winthrop KL, Baddley JW. Pneumocystis and glucocorticoid use: to prophylax or not to prophylax (and when?); that is the question. Ann Rheum Dis. 2018;77(5):631-3.

14. Cettomai D, Gelber AC, Christopher-Stine L. A survey of rheumatologists' practice for prescribing pneumocystis prophylaxis. $J$ Rheumatol. 2010;37(4):792-9.

Ready to submit your research? Choose BMC and benefit from:

- fast, convenient online submission

- thorough peer review by experienced researchers in your field

- rapid publication on acceptance

- support for research data, including large and complex data types

- gold Open Access which fosters wider collaboration and increased citations

- maximum visibility for your research: over $100 \mathrm{M}$ website views per year

At BMC, research is always in progress.

Learn more biomedcentral.com/submissions 